\title{
Joint analysis by the Nordic countries of a hepatitis A outbreak, October 2012 to June 2013: frozen strawberries suspected
}

Nordic outbreak investigation team

1. The members of the group are listed at the end of the article

Citation style for this article:

Nordic outbreak investigation team. Joint analysis by the Nordic countries of a hepatitis A outbreak, October 2012 to June 2013 : frozen strawberries suspected. Euro Surveill. 2013;18(27):pii=20520. Available online: http://www.eurosurveillance.org/ViewArticle.aspx?Articleld=20520

Article submitted on 24 June 2013 / published on 04 July 2013

The Nordic countries faced a food-borne outbreak of hepatitis A that started in October 2012 and was ongoing with 103 reported cases as of 27 June 2013. A case-control study in Denmark, Finland, Norway and Sweden, combined with trace-back investigations, has identified frozen strawberries as the likely cause of the outbreak. The origin of the berries is still being investigated.

Hepatitis A seroprevalence is under $10 \%$ in Nordic countries [1] where endemicity is very low [2]. In February 2013, Denmark noticed an increase in the number of notified hepatitis A virus (HAV) infections among individuals with no travel history. On 1 March 2013, following an urgent enquiry posted through the European Epidemic Intelligence Information System for food- and waterborne diseases (EPIS-FWD), Finland, Norway and Sweden reported a similar increase and identified cases that were infected with the same IB genotype and sequence (KC876797) as the Danish cases, as well as cases with closely related sequences [3]. In March 2013, a case-control study conducted in Denmark identified frozen berries, particularly frozen strawberries, as the likely vehicle of the outbreak, but could not exclude other frozen berries [3]. As a result of this finding, the four Nordic countries recommended boiling all frozen berries before consumption [3].

While public health institutes in the four country coordinated their data collection methods to pool the analysis of the country-specific case-control studies to identify the vehicle of the outbreak more precisely, investigators compared the outbreak strains with the HAV network (HAVNET) database [4] to gain information on the probable phylogenetic origin of the outbreak strains, and food agencies analysed product distribution and tested fruit specimens.

\section{Methods}

\section{Case definitions}

A probable case was defined as a person living in Denmark, Finland, Norway or Sweden who developed clinical illness compatible with HAV infection on or after* 1 October 2012 (1 December 2012 for Sweden) and was positive for IgM antibodies against HAV. We excluded cases who (i) reported travel outside of Western European countries two to six weeks before onset of symptoms, (ii) were living in the same household as a patient with HAV infection typed with a genotype or sequence not belonging to the outbreak and (iii) reported other risk factors for hepatitis A exposure including injection drug use, homelessness or male-tomale sexual contact (the exposures under (iii) were not ascertained in Swedish and Finnish cases).

A confirmed case was defined as a probable case infected with HAV genotype $1 B$ with the sequence identified by GenBank number KC 876797 (hereafter called sequence 1) or a sequence that differed by no more than $2 \%$ from sequence KC 876797 [3], and was isolated in at least two of the four affected countries.

A secondary case was defined as a probable or confirmed case with symptom onset two to six weeks after close contact with a primary probable or confirmed case.

\section{Descriptive epidemiology}

We described the distribution of cases by age, sex, country of residence, disease status (confirmed, probable, secondary) and HAV sequence.

\section{Case-control studies}

Each country conducted a matched case-control study based on the Danish case-control study protocol, modified according to findings from their own trawling questionnaires. Early and regular communication by email and teleconferences, as well as sharing of study plans and questionnaires, ensured that data could be used for joint analysis.

Control selection and invitation

Each country randomly selected controls using national population registries, matched on age, sex and place of residence (municipality in Denmark, Norway and 
Distribution of hepatitis A cases over time, Denmark, Finland, Norway and Sweden, October 2012-June 2013 (n=103)

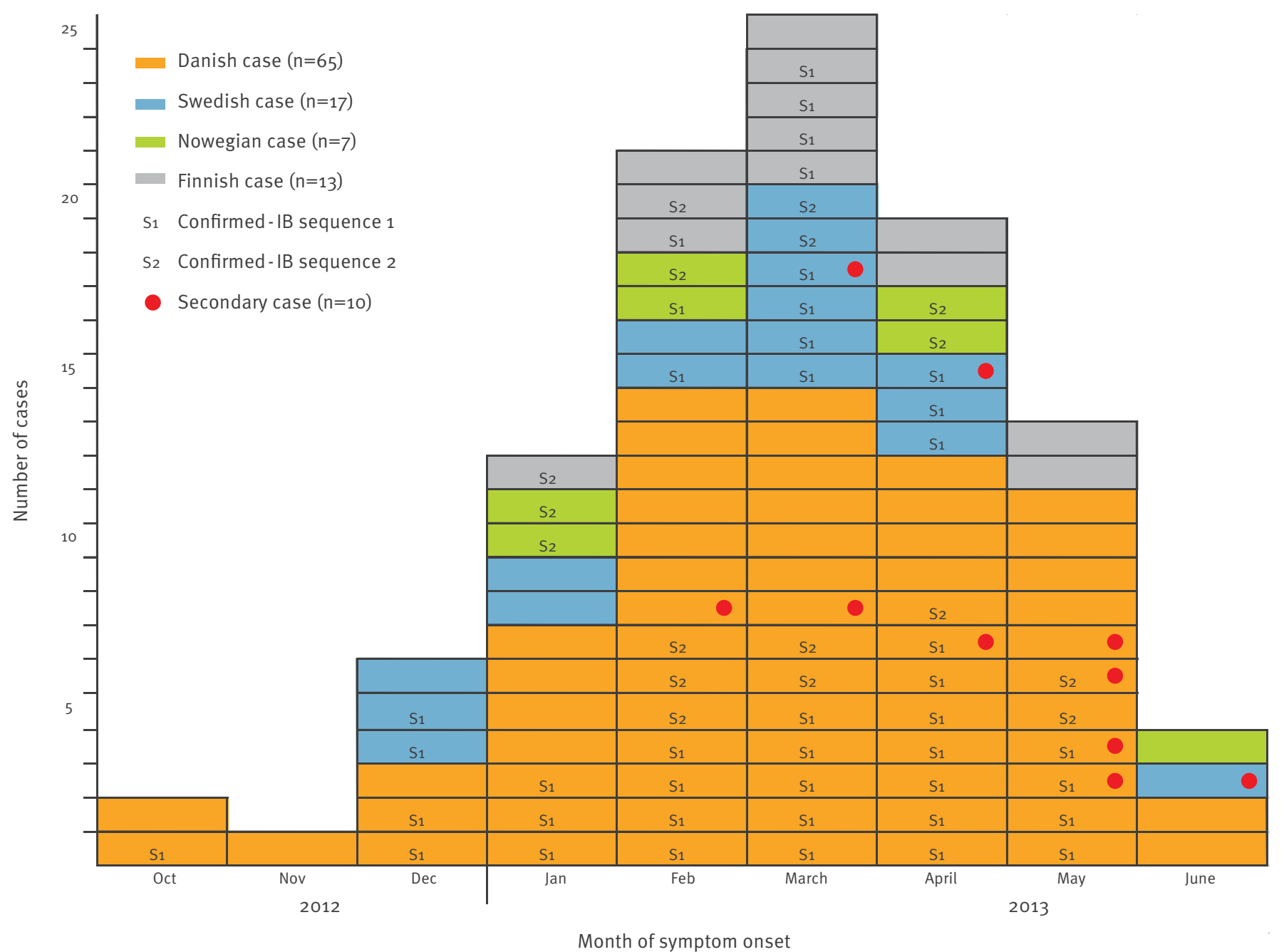

Finland; county in Sweden). Controls were excluded if they were vaccinated against HAV, reported a previous HAV infection, or if they had been travelling for more than two weeks in western Europe or any length of time outside of western Europe in the six weeks prior to recruitment.

\section{Data collection}

In Denmark, investigators telephoned potential controls until two controls per case had been recruited. In Norway, the same procedure was followed for two to three controls per case. Sweden invited six controls per case by post and Finland invited 30 controls per case, by phone. The latter two countries included all controls who accepted the invitation.

Cases and controls were asked about the consumption of a range of food items, including berries, during the six weeks before onset of illness (cases) or recruitment (controls). Norway asked controls about exposures during the period corresponding to the exposure period of the cases (January to February 2013).

\section{Data analysis}

The pooled analysis regrouped primary confirmed cases included in the national studies with at least one matched control (Denmark, Norway, Sweden) or before 24 May (Finland). The strength of the association between HAV infection and consumption of food items present in at least three country questionnaires was estimated using matched odds ratio ( $\mathrm{mOR}$ ) and 95\% confidence intervals $(\mathrm{Cl})$ using conditional logistic regression. Statistically significant exposures at the alpha $=0.05$ level were fitted in a multivariable conditional logistic regression model to adjust for confounding. We stratified the analysis by HAV sequence isolated in cases [3] and compared cases with HAV sequence 1 and cases with HAV sequence 2 in terms of consumption of berries using Fisher's exact test. 
Frequency of selected exposures among confirmed hepatitis A cases $(n=26)$ and controls $(n=56)$ in a matched analysis by the Nordic countries ${ }^{\mathrm{a}}$ and an unmatched analysis in Sweden, October 2012-June 2013

\begin{tabular}{|c|c|c|c|c|c|c|c|c|c|c|c|c|}
\hline \multirow{3}{*}{ Exposure } & \multicolumn{10}{|c|}{ Multicountry investigation } & \multirow{2}{*}{\multicolumn{2}{|c|}{$\begin{array}{c}\text { National investigation } \\
\text { Sweden }^{\mathrm{b}}\end{array}$}} \\
\hline & \multicolumn{3}{|c|}{ Cases } & \multicolumn{3}{|c|}{ Controls } & \multirow{2}{*}{$\begin{array}{l}\text { Crude } \\
\text { mOR }\end{array}$} & \multirow{2}{*}{$95 \% \mathrm{Cl}$} & \multirow{2}{*}{$\begin{array}{l}\text { Adjusted } \\
\text { mOR }\end{array}$} & \multirow{2}{*}{$95 \% \mathrm{Cl}$} & & \\
\hline & Total & Exposed & $\%$ & Total & Exposed & $\%$ & & & & & $\begin{array}{l}\text { Odds } \\
\text { Ratio }\end{array}$ & $95 \% \mathrm{Cl}$ \\
\hline Frozen strawberries & 26 & 22 & 84.6 & 53 & 19 & $35 \cdot 9$ & 8.8 & $2.5-30.5$ & 11.4 & $1.9-69.9$ & 24.5 & $\begin{array}{c}1.9- \\
1179.7\end{array}$ \\
\hline Frozen raspberries & 25 & 16 & 64.0 & 54 & 16 & 29.6 & 7.3 & $2.1-26.0$ & 5.1 & $0.9-26.4$ & 2.1 & $0.3-18.4$ \\
\hline Berries in smoothie & 21 & 15 & 71.4 & 44 & 13 & $29 \cdot 5$ & 8.3 & $1.8-37.8$ & - & - & 6.7 & $0.7-69.7$ \\
\hline Frozen mixed berries & 25 & 8 & 32.0 & 51 & 5 & 9.8 & 10.6 & $1.3-86.4$ & 11.4 & $0.9-132.7$ & 0.8 & $0.0-13.2$ \\
\hline Berries in other forms & 19 & 9 & $47 \cdot 4$ & 45 & 8 & 17.8 & 2.4 & $0.5-7.2$ & - & - & 2.7 & $0.3-23.7$ \\
\hline Other frozen berries & 21 & 6 & 28.6 & 41 & 5 & 12.2 & 3.6 & $0.9-15.1$ & - & - & 1.5 & $0.0-34.5$ \\
\hline Frozen blueberries & 24 & 11 & 45.8 & 53 & 15 & 28.3 & 2.6 & $0.9-7.6$ & - & - & 0.7 & $0.0-9.9$ \\
\hline Berries in desert & 22 & 11 & 50.0 & 45 & 16 & 35.6 & $3 \cdot 7$ & $0.9-14 \cdot 5$ & - & - & 1 & $0.1-7.3$ \\
\hline Nuts & 13 & 10 & 76.9 & 34 & 25 & 73.5 & 1.6 & $0.3-9.4$ & - & - & 0.85 & $0.1-7.7$ \\
\hline Grapes & 13 & 11 & 84.6 & 33 & 27 & 81.8 & 1.8 & $0.3-10.1$ & - & - & 3.5 & $0.3-188.8$ \\
\hline
\end{tabular}

$\mathrm{Cl}$ : confidence interval; mOR: matched odds ratio.

Denmark, Finland, Norway, Sweden.

Unmatched study, eight cases (confirmed), 18 controls.

The Swedish case-control study (including confirmed cases only) was also analysed individually. As controls could not be recruited for every case, the match was broken (after checking that matched and unmatched ORs were of the same magnitude) and odds ratios (OR) with $95 \% \mathrm{Cl}$ were calculated using logistic regression, adjusting for age.

\section{Identification of strain origin}

Laboratory confirmation of the cases has been described previously [3]. To look for indications of the geographical origin of the outbreak strains, we analysed the phylogeny using the HAVNET database that contains sequence data of viruses from patients from non-endemic countries, many of whom contracted the infection in a foreign country $(67 \%$ of sequences in HAVNET are from isolates from Dutch patients). A total of 442 nucleotides in the VP1-P2A region and 466 nucleotides in the $\mathrm{VP}_{1}$ region of the genome were analysed separately. The probable origin of the cluster of sequences including the outbreak strains was ascertained as previously described [5].

\section{Product distribution analysis}

In Norway and Denmark sales receipts obtained from the cases were used to ascertain the types and brands of berries purchased before symptom onset. Supermarkets chains assisted in tracing suppliers and countries of origin of the berries.
Danish, Finnish, Norwegian and Swedish, national food authorities collected soft fruit specimens (berries and mango) from confirmed cases' freezers and from shops selling suspected batches. Denmark, Norway and Sweden analysed the specimens applying the same standardised HAV detection method [6] based on reverse transcriptase polymerase chain reaction (RT-PCR). In addition, Denmark and Norway followed a protocol specifically developed for soft fruits [7]. Specimens from Finland were tested in Denmark.

\section{Results}

As of 27 June 2013, 103 cases (59 confirmed, 34 probable and 10 secondary) were reported, 66 in Denmark, 17 in Sweden, 13 in Finland and seven in Norway (Figure 1). The age range was 4-76 years (median: 24 years) and $61 \%$ were female. No cases with the outbreak sequences were excluded because of other hepatitis A risk factors. The most recent case (as of June 27) was reported in Norway (illness onset 14 June 2013). Sequence 1) was isolated from 42 of 59 confirmed cases, whereas a second sequence with $1.7 \%$ difference to sequence 1 over 847 bp (GenBank accession number KC876799, hereafter called sequence 2) was isolated from 17 of 59 cases.

\section{Case-control studies}

After excluding cases that did not have a matched control, the multicountry analysis included 26 confirmed cases (Denmark: 12, Sweden: 6, Norway: 4, Finland: 


\section{FIGURE 2}

Comparison of hepatitis A virus sequences included in the HAVNET database with the two sequences involved in the outbreak in the Nordic countries ${ }^{\mathrm{a}}$, October 2012-June 2013

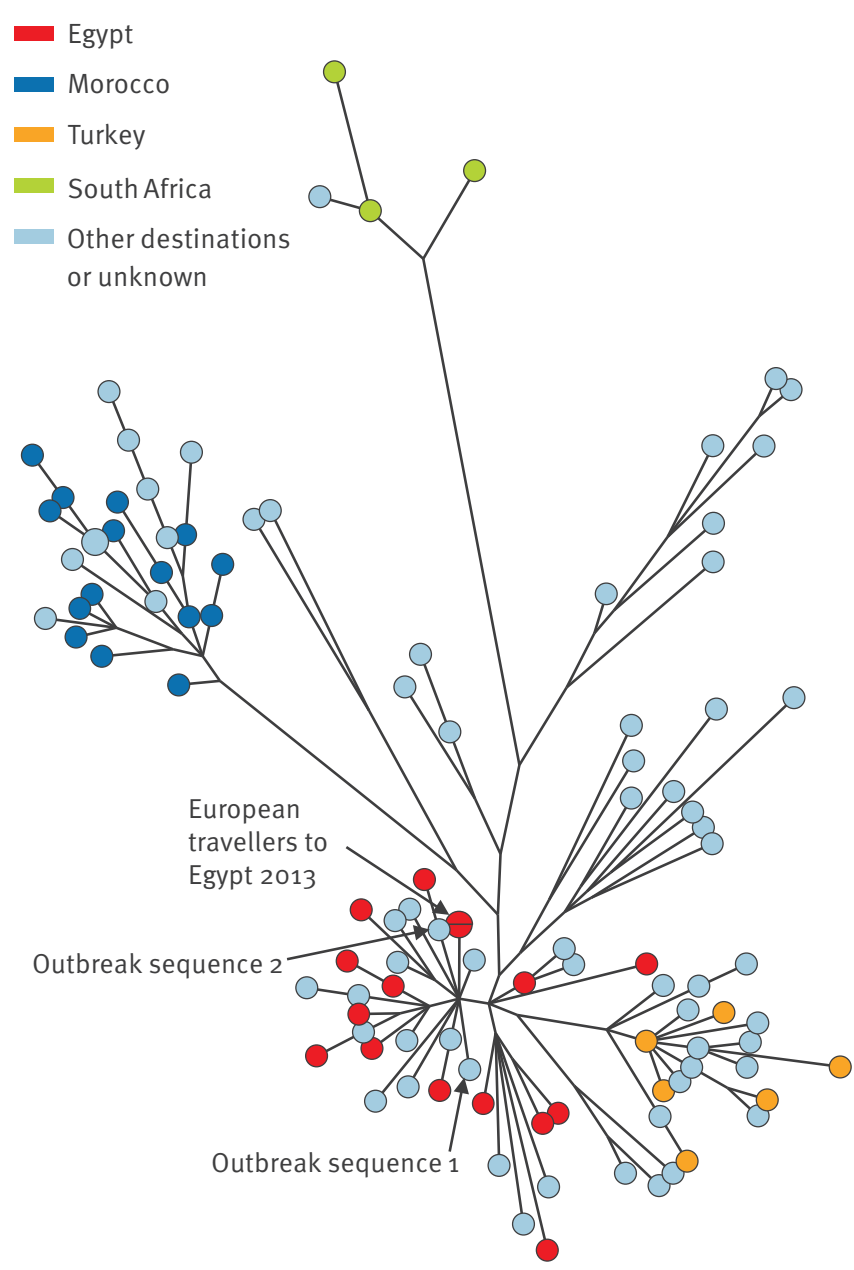

a Denmark, Finland, Norway, Sweden.

Maximum parsimony tree of 442 nucleotides of the VP1/2A junction region of hepatitis $A$ virus type IB, using 253 sequences deposited in the Dutch HAVNET database. This database contains $67 \%$ Dutch travellers. The two sequences involved in the outbreak in the Nordic countries are indicated by arrows

4) and 56 controls, with one to five controls per case. In the univariable analysis, eating frozen strawberries (mOR 8.8; $95 \% \mathrm{Cl} 2.5-30$ ), frozen raspberries ( $\mathrm{mOR} 7.3$; $95 \% \mathrm{Cl}$ 2.1-26), berry-containing smoothies (mOR 8.3; $95 \% \mathrm{Cl} 1.8-38$ ) and frozen mixed berries (mOR 11; $95 \%$ Cl 1.3-86, Table) was associated with being a case. Of the 26 confirmed cases, 22 reported eating frozen strawberries, 16 reported eating frozen raspberries, and eight reported eating frozen mixed berries. When including strawberries, raspberries and mixed berries in a multivariable model, only strawberries remained significantly associated with being a confirmed case
(mOR 11.4; 95\% Cl 1.9-70, Table). When restricting the analysis to cases with sequence 1 , eating strawberries and raspberries were both associated with HAV infection (crude mOR 6.1; 95\% Cl 1.7-22 and mOR 5.6; 95\% Cl 1.1-27, respectively). However, only eating strawberries was associated with being a confirmed case in multivariable analysis (mOR $5.8 ; 95 \% \mathrm{Cl} 1.2-27$ for strawberries, mOR $5.3 ; 95 \% \mathrm{Cl} 0.77-36$ for raspberries). When restricting the analysis to cases with sequence 2, eating frozen raspberries was also associated with being a confirmed case (crude mOR 11; 95\% $\mathrm{Cl}$ 1.3-92). Since all sequence 2 cases consumed frozen strawberries, an $\mathrm{mOR}$ for frozen strawberries could not be calculated, but the association was statistically significant. Cases with sequence 1 were as likely to have eaten strawberries and raspberries as cases with sequence 2 (Fisher's exact test: $p=0.54$ and $p=0.35$, respectively).

The Swedish case-control study included eight confirmed cases and 18 controls. Frozen strawberries were the only exposure significantly associated with HAV infection (crude OR: $24 ; 95 \% \mathrm{Cl} 1.9-1,200$ ) (Table), which remained significant after adjusting for age (OR: 82; 95\% Cl 1.7-3,929).

\section{Identification of strain origin}

The most frequently represented countries of infection included in HAVNET were Egypt $(n=30)$, Morocco $(n=21)$ and Turkey $(n=15)$. All samples were from travellers. A comparison of the two investigated genomic regions indicated that the outbreak strains were associated with strains commonly isolated in travellers infected in Egypt (p<0.001, Figure 2). Sequence 1 and 2 differed by $1.22 \%$ over 1,233 bp and by $1.26 \%$ over 397 bp, respectively, from the strain causing a concurrent outbreak in travellers returning from Egypt [4].

\section{Product investigation analysis}

As of 27 June, 54 soft fruit specimens ( 17 from Denmark, 14 from Finland, 11 from Sweden, 12 from Norway) were tested, 23 of which were strawberries. HAV was not detected in any of the specimens.

Trace-back analysis was ongoing as of 27 June 2013, pointing at strawberries from several countries.

\section{Public health actions}

On 22 May 2013 Public Health and Food agencies in Denmark, Finland and Norway issued statements identifying strawberries as the likely vehicle of the outbreak, but maintained previous recommendations to boil all frozen berries before consumption due to the potential implication of other berries. Sweden restricted the boiling notice to strawberries only. On 30 May 2013, one supermarket chain in Denmark, Norway and Sweden voluntarily recalled frozen strawberries from Egypt and Morocco packed in Belgium $[8,9]$. 


\section{Discussion}

After pooling data from the four affected countries, consumption of frozen strawberries, frozen raspberries and mixed frozen berries (which can contain both strawberries and raspberries) were significantly associated with being a confirmed case. Although the pooled analysis was restricted to earlier confirmed cases, this is unlikely to have introduced bias since there was no reason to believe later cases were different from earlier ones. Hepatitis A outbreaks have been previously linked to both strawberries $[10,11]$ and raspberries $[12,13]$, and frozen mixed berries are suspected in two hepatitis A outbreaks that were ongoing as of 27 June 2013 in Italy and the United States (US) [14,15]. Frozen strawberries were most strongly associated with being a confirmed case and were the product most commonly eaten by cases. Additional elements pointed to the strawberries as the vehicle of the outbreak: Firstly, strawberries were most strongly associated with being a case in the Swedish national case-control study as well as national case-control studies in Denmark and Norway [3]. Secondly, strawberries were the only exposure significantly associated with being a confirmed case in the multicountry multivariable analysis. Thirdly, the preliminary food trace-back investigations pointed towards strawberries. Finally, when restricting the analysis to individuals who did not consume raspberries, the association between being a confirmed case and frozen strawberries remained significant.

The strength of association between raspberries and being a confirmed case in the multicountry analysis was weaker than for strawberries. In addition, raspberries were not associated with illness in the Swedish study. Restricting the analysis to people who had not eaten strawberries was difficult because only four cases did not eat strawberries. Trace-back analysis found no evidence to implicate raspberries, but based on the epidemiological analyses, we cannot completely exclude that raspberries or frozen mixed berries may have played a role in the outbreak.

The outbreak included two distinct (less than $2 \%$ different) HAV sequences that were found in the four countries during the outbreak period. There was no evidence that one outbreak strain was more strongly associated with one vehicle than the other. The HAV mutation rate is low [16], suggesting the two sequences identified in the outbreak represented distinct strains rather than a sporadic mutation. Such multi-strain food-borne hepatitis $A$ outbreaks have been reported previously $[17,18]$. At this stage we do not know where in the production chain or in which country the contamination occurred. While the comparison of strains in the HAVNET database indicated an association with strains from travellers infected in Egypt, we cannot exclude that these strains also circulate in other countries. As HAV is not genotyped routinely, the known genetic diversity is biased towards more densely sampled regions. Finally, the trace-back investigation has not yet pointed to a single country. The origin of the contaminated strawberries or the point of contamination can therefore not be identified at this moment.

This outbreak occurred in the context of several hepatitis A outbreaks affecting Europe and EU residents $[4,14,19]$ as well as another genotype $1 B$ outbreak in the US related to frozen mixed berries [15]. The US and Nordic HAV strains are both genotype $1 \mathrm{~B}$ and originate from the same geographic region but there is no evidence so far they are related [15].

HAV has as yet not been detected in the tested berries. Possible reasons could be that the HAV concentration in the samples collected may have been below the detection limit, or that other berries from the same batch contained HAV.

In conclusion, during this outbreak, combined evidence from case-control studies and the food traceback contributed to implicate frozen strawberries as the source of the outbreak, leading one supermarket chain voluntary recall this product. Investigations of the source will continue in order to identify the producer and batch and to test berries in the laboratory. In view of the long incubation period of hepatitis A [20] and of notification delay, more cases can be expected to occur for at least another few months, and possibly even later, despite interventions, as frozen berries can be stored in freezers for up to two years.

\section{Acknowledgements}

Denmark: We wish to thank all notifying physicians and the interviewers, Laura Espenhain, Julie M K Nielsen, Timmy Nielsen and Caroline B Andersen, SSI, for their assistance in interviewing cases and controls in the Danish case-control study and the regional food authorities in Denmark for collecting berry samples from cases. Additionally, we would like to thank all the laboratory departments and general practitioners in Denmark for sending HAV samples for testing and further characterisation at the Department of Microbiological Diagnostics and Virology (MDV), SSI. We are most grateful for the highly skilled expertise provided by laboratory technicians Camilla Dalgaard and Shukriye Barzinci at the MDV, $\mathrm{SSI}$, in the genotypic characterisation of HAV strains.

Norway: We thank the employees at the Norwegian Food Authorities for conducting interviews and collecting berry samples, Heidi Lange and Kirsten Kosmo of the Norwegian Public Health Institute for help with the case-control study, and Hilde Elshaug for help in the laboratory.

Sweden: We thank all infection control physician who interviewed cases. Thanks to Ahmed Farah at the Swedish Institute for Communicable Disease Control for helping with interviewing cases and controls and conducting trawling questionnaires.

Finland: We would like to thank the municipal food control and health authorities as well as clinical laboratories for collecting and analysing the samples and notifying the cases. We would also like to thank Marjaana Hakkinen of the National Reference Laboratory for coordinating and sending food samples, and Anna Charlotte Schultz of the Division of Food Microbiology of the Technical University of Denmark for the analyses of the Finnish food samples.

Members of the Nordic outbreak investigation team: 
Denmark:

Department of Infectious Disease Epidemiology, Statens Serum Institut, Copenhagen:

Steen Ethelberg, Sofie Gillesberg Lassen, Kåre Mølbak, Bolette Soborg. Department of Microbiological Diagnostics and Virology, Statens Serum Institut,Copenhagen:

Thea Kølsen Fischer, Ann Sofie Hintzmann, Sofie Elisabeth Midgley, Hanne Thang Vestergaard.

Danish Veterinary and Food Administration: Tenna Jensen.

Danish Technical University, Food Institute: Anna Charlotte Schultz. European Programme for Intervention Epidemiology Training (EPIET), European Centre for Disease Prevention and Control (ECDC:) Stockholm, Sweden: Bolette Soborg.

Finland:

National Institute for Health and Welfare, Helsinki: Sari Huusko, Mia Kontio, Ruska Rimhanen-Finne, Salla Toikkanen. Finnish Food Safety Authority, Helsinki: Hanna Lundstrom, Annika Pihlajasaari.

The Netherlands:

National Institute for Public Health and the Environment, Bilthoven (HAVNET reference database): Marion Koopmans, Harry Vennema, Linda Verhoef.

Norway:

Norwegian Institute of Public Health, Oslo: Anneke Steens, Kathrine Stene-Johansen Line Vold.

Norwegian Food Safety Authority, Oslo: Laila Jensvoll, Marit Lilleby, Torunn Stalheim.

Norwegian School of Veterinary Science, Oslo: Mette Myrmel. European Programme for Intervention Epidemiology Training (EPIET), European Centre for Disease Prevention and Control (ECDC), Stockholm, Sweden: Anneke Steens.

Sweden:

Swedish Institute for Communicable Disease Control, Stockholm: Michael Edelstein, Margareta Löfdahl, Lena Sundqvist, Anders Wallensten.

Swedish National Food Agency, Stockholm: Rickard Bjerselius, Christina Lantz, Mats Lindblad, Magnus Simonsson, Christina Spens.

European Programme for Intervention Epidemiology Training (EPIET), European Centre for Disease Prevention and Control (ECDC), Stockholm, Sweden: Michael Edelstein.

\section{Conflict of interest}

None declared.

\section{Authors' contributions}

ME contributed to the study design, collection and analysis of data for the joint case-control study, led the Swedish case-control study and drafted the manuscript as the lead writer. SGL contributed to the study design and was in charge of the joint descriptive epidemiology.BS contributed to the study design and led the Danish case-control study.SEM and HTV contributed to the laboratory sequencing and analysis in Denmark. TKF contributed to interpretation of the virological data in Denmark.TJ was in charge of the trace-back in Denmark and drafted the trace-back section of the manuscript.KM and SE contributed to the design of the Danish case-control study and to the epidemiological investigations. AS contributed to the study design. AS and LV were in charge of the epidemiological investigations including the case-control study in Norway. LJ was in charge of the trace-back investigation of in Norway, with assistance from ML and TS. KSJ was in charge of the laboratory typing and analysis in Norway. RRF was in charge of the epidemiological investigations in Finland.MK was in charge of the laboratory typing and analysis in Finland. HL was in charge of the trace-back in Finland. ML were in charge of the epidemiological investigations in Sweden. LS was in charge of the laboratory typing and analysis in Sweden.MS was in charge of the trace back in Sweden. LV, HV and MK were in charge of the phylogenic analysis. SGL, KM, BS, TKF, TJ, AS, LV, LJ, RRF, HL, ST, ML, LS, AW, MS, LV, MK reviewed the first draft of the paper. All authors approved the final version.

\section{*Authors' correction:}

On request of the authors, the probable case definition was corrected from "after 1 October 2012" to "on or after 1 October 2012". This change was made on 4 July, 20:15.

\section{References}

1. Jacobsen H. The Global Prevalence of Hepatitis A Virus Infection and Susceptibility: A Systematic Review. Geneva: World Health Organization; 2009. Available from: http:// whqlibdoc.who.int/hq/2010/WHO_IVB_10.01_eng.pdf

2. World Healh Organization (WHO). Global Alert and Response. Hepatitis A - an introduction. Geneva: WHO. [Accessed:17 June 2013]. Available from: http://www.who.int/csr/disease/ hepatitis/whocdscsredc2007/en/index1.html\#world

3. Gillesberg Lassen S, Soborg B, Midgley SE, Steens A, Vold L, Stene-Johansen K, et al. Ongoing multi-strain food-borne hepatitis A outbreak with frozen berries as suspected vehicle: four Nordic countries affected, October 2012 to April 2013. Euro Surveill. 2013:18(17):pii=20467. Available from: http:// www.eurosurveillance.org/ViewArticle.aspx?Articleld $=\mathbf{2 0 4 6 7}$

4. Macdonald E, Steens A, Stene-Johansen K, Gillesberg Lassen S, Midgley SE, Lawrence J, et al. Increase in hepatitis A in tourists from Denmark, England, Germany, the Netherlands, Norway and Sweden returning from Egypt, November 2012 to March 2013. Euro Surveill. 2013;18(17): $\mathrm{pii}=20468$. Available from: http://www.eurosurveillance.org/ViewArticle. aspx?Articleld=20468 PMid:23647624

5. Verhoef L, Kouyos RD, Vennema H, Kroneman A, Siebenga J, van Pelt W, et al. An integrated approach to identifying international foodborne norovirus outbreaks. Emerg Infect Dis. 2011;17(3):412-8. http://dx.doi.org/10.3201/eid1703.100979 PMid:21392431 PMCid:PMC3166008

6. Internation Standards Organization (ISO). ISO/TS 152162:2013: Microbiology of food and animal feed -- Horizontal method for determination of hepatitis A virus and norovirus in food using real-time RT-PCR -- Part 2: Method for qualitative detection. Geneva: ISO; 2013. Available from: http://www. iso.org/iso/home/store/catalogue_tc/catalogue_detail. htm?csnumber $=60297$

7. Struve J, Bennet R, Ehrnst A, Eriksson M, Hedlund KO, Herin $\mathrm{P}$, et al. Nosocomial calicivirus gastroenteritis in a pediatric hospital. Pediatr Infect Dis J. 1994;13(10):882-5. http://dx.doi. org/10.1097/00006454-199410000-00007 PMid:7854887

8. Danish Food Agency. Jordbær fra Egypten og Marokko sandsynlig kilde til Hepatitis A. [Strawberries from Egypt and Morocco likely source of Hepatitis A]. Glostrup: Danish Food Agency; 2013. Danish. Available from: http://www. foedevarestyrelsen.dk/Nyheder/Nyheder/Arkiv_2013/Sider/ Jordbær-fra-Egypten-og-Marokko-sandsynlig-kilde-tilHepatitis-A.aspx

9. Norwegian Food Safety Authority. Coop tilbakekaller fryste jordbær fra markedet. [Coop recalls frozen strawberries from the market]. Brumunddal: Norwegian Food Safety Authority; 2013. Norwegian. Available from: http://www.mattilsynet.no/mat_og_vann/ smitte_fra_mat_og_drikke/virus_i_mat_og_drikke/ coop_tilbakekaller_fryste_jordbaer_fra_markedet

10. Hutin YJ, Pool V, Cramer EH, Nainan OV, Weth J, Williams IT, et al. A multistate, foodborne outbreak of hepatitis A. National Hepatitis A Investigation Team. N Engl J Med. 1999;340(8):595602. http://dx.doi.org/10.1056/NEJM199902253400802 PMid:10029643

11. Niu MT, Polish LB, Robertson BH, Khanna BK, Woodruff BA, Shapiro CN, et al. Multistate outbreak of hepatitis A associated with frozen strawberries. J Infect Dis. 1992;166(3):518-24. http://dx.doi.org/10.1093/infdis/166.3.518 PMid:1323618

12. Reid TM, Robinson HG. Frozen raspberries and hepatitis $A$. Epidemiology and Infection. 1987;98(1):109-12. http://dx.doi.org/10.1017/So95026880006177X

13. Ramsay CN, Upton PA. Hepatitis $A$ and frozen raspberries. Lancet. 1989;1(8628):43-4. http://dx.doi.org/10.1016/ S0140-6736(89)91698-X

14. European Centre for Disease Prevention and Control (ECDC). Joint ECDC-EFSA assessment: outbreak of hepatitis A virus infection in residents and travellers to Italy. Stockholm: ECDC; 
2013. Available from: http://ecdc.europa.eu/en/publications/ Publications/hepatitis-A-outbreak-of-hepatitis-A-virus-

infection-in-residents-and-travellers-to-ltaly.pdf

15. Centres for Disease Control and Prevention (CDC). Multistate outbreak of hepatitis A virus infections linked to pomegranate seeds from Turkey. Atlanta: CDC. [Accessed 7 Jun 2013]. Available from: http://www.cdc.gov/hepatitis/Outbreaks/2013/ A1b-03-31/

16. Verhoef L, Boxman IL, Koopmans M. Viruses transmitted through the food chain: a review of the latest developments.

CAB Reviews: Perspectives in Agriculture, Veterinary Science, Nutrition and Natural Resources. 2008;3(78). Available from: www.vwa.nl/txmpub/files/?p_file_id=32790 http://dx.doi. org/10.1079/PAVSNNR20083078

17. Fournet $N$, Baas D, van Pelt W, Swaan C, Ober HJ, Isken L, et al. Another possible food-borne outbreak of hepatitis $A$ in the Netherlands indicated by two closely related molecular sequences, July to October 2011. Euro Surveill. 2012;17(6):pii=20079. Available from: http://www. eurosurveillance.org/ViewArticle.aspx?Articleld =20079 PMid:22340976

18. Carvalho C, homas HL, Balogun K, Tedder R, Pebody R, Ramsay $M$, et al. A possible outbreak of hepatitis A associated with semi-dried tomatoes, England, July-November 2011. Euro Surveill. 2012;17(6):pii=20083. Available from: http://www. eurosurveillance.org/ViewArticle.aspx?Articleld=20083

19. Dakic Z, Musa S. Hepatitis A outbreak in Bijeljina, Bosnia and Herzegovina, August 2012 - April 2013 Euro Surveill. 2013;18(21): pii=20486. Available from: http://www. eurosurveillance.org/ViewArticle.aspx?Articleld=20486 PMid:23725978

20. Heymann DL (editor). Control of communicable diseases manual. 19th ed. Washington, DC: American Public Health Association; 2008. 746 pp. 